\title{
O MUSEU DE GEOCIENNCIAS DA UFPA
}

Danielle da Silva Gomes

Graduanda do curso de Bacharelado em Museologia pela Universidade Federal do Pará (UFPA). Bolsista do Programa de Apoio ao Doutor Pesquisador (PRODOUTOR). E-mail: danielle.musealia@gmail.com

Wanessa Pires Lott

\begin{abstract}
Possui graduação em História pela Universidade Federal de Minas Gerais e mestrado em Ciências Sociais/Gestão de Cidades pela PUC/MG e em Antropologia pela UFMG. Doutora pelo Programa de Pós Graduação em História da UFMG e professora do curso de museologia da UFPA. Tem experiência na área de História e Antropologia. E-mail:wanessalott@ hotmail.com
\end{abstract}

\section{RESUMO}

O objetivo deste trabalho consiste em uma abordagem sobre o Museu de Geociências da Universidade Federal do Pará (GEOMU/UFPA). Por se tratar de um museu vinculado à referida universidade, o tratamento do mesmo se amplia na tipologia de 'museu universitário', termo este que será apresentado no estudo. Ademais, como GEOMU faz parte da categoria de 'museu de ciência e da técnica' este conceito também será a presentada. Os dados da pesquisa foram baseados não só em pesquisas bibliográficas como também na pesquisa in loco e entrevista realizada com um dos técnicos responsáveis pelo referido museu.

PALAVRAS-CHAVE: Museu Universitário; Museus de Ciência e da Técnica; Museu de Geociências da Universidade Federal do Pará.

\section{UFPA'S GEOSCIENCE MUSEUM}

\begin{abstract}
The objective of this paper is to approach the Geosciences Museum of the Federal University of Pará (GEOMU / UFPA). Because it is a museum linked to that university, its treatment is expanded in the typology of "university museum", a term that will be presented in the study. Moreover, as GEOMU is part of the category of 'museum of science and technique' this concept will also be the one presented. The research data were based not only on bibliographic searches, but also on-site research and interviews with one of the technicians responsible for the museum.
\end{abstract}

KEYWORDS: University Museum; Science and Technique Museums; Geosciences Museum of the Federal University of Pará. 


\section{INTRODUÇÃO}

Os museus tem sua origem na Grécia antiga, cujas palavras mouseion e mousa, foram suas primeiras denominações. Ligado ao templo das musas, filhas de Zeus e Mnemosine. Eram locais ligados à memória e às diversas formas de estudo das ciências, das artes ciência, além de ser um local para contemplação e para sacralidade (ROSÁRIO, 2002).

Nos Tempos Modernos, os museus passam a ser originários dos gabinetes de curiosidades, que por sua vez eram vinculados majoritariamente às elites. A partir de meados do século XX, os museus começam a tornar espaços mais acessíveis a uma diversidade de públicos, não mais restritos somente a uma parcela privilegiada e endinheirada. Sua função passa a ter um forte caráter educativo, ou seja, para além do entretenimento, o papel dos museus é informar e disseminar a diversidade de saberes e culturas, propagando assim as memórias que estão ligadas intrinsecamente aos objetos que o compõem.

Neste sentido, os museus são atualmente definidos pelo Internation Council of Museums $(\mathrm{ICOM})^{1}$ como uma instituição permanente que não apresenta fins lucrativos e está a serviço da sociedade, bem como de desenvolvimento. Apesar de, para a maioria do público, os museus ainda serem visto apenas locais de exposição, estes têm como função adquirir, conservar, investigar e difundir os testemunhos da humanidade como intuito de contribuir para a educação e deleite social (ICOM, 2019).

Dentre as tipologias nas quais os museus são caracterizados estão: museus de arte, museus de história natural, museus de etnografia e folclore, museus históricos, museus de ciências sociais e serviços sociais, museus de comércio e das comunicações, museus de agricultura e produtos da terra e museus de ciências e técnicas. Este último tipo terá o maior foco nesta pesquisa, e, aliado a este, tomemos também a tipologia por meio da propriedade. Dentre as possibilidades dos museus serem privados, estatais, municipais, eclesiásticos e universitários. A conformação de 'museus universitários' será uma das linhas do trabalho.

Diante do exposto, este artigo parte da apresentação do Museu de Geociências (MUGEO), que está vinculado à Universidade Federal do Pará (UFPA), para discutir os conceitos de 'museu de ciências e da técnica' e 'museu universitário'. Assim sendo, se faz necessária primeiramente a apresentação do objeto de estudo e á medida que as características

${ }^{1} \mathrm{Na}$ Assembleia geral do ICOM realizada em setembro de 2019 em Kyoto, foi aberta debates para a alteração do conceito de museus já estabelecido. No entanto, ainda não foi divulgado os resultados desta discussão. 
do MUGEO forem demonstradas, o debate tipológico e conceitual será demonstrado.

Para além de tal problematização, pretendemos demonstrar a relevância deste museu no cenário educacional da Amazônia, por propiciar a comunicação dos conhecimentos produzidos na universidade para a comunidade interna e externa. Os dados que aportam esta análise são os estudos bibliográficos sobre a temática e a pesquisa de campo no referido museu. Por meio de uma observação in loco, uma entrevista com um dos responsáveis pelo museu e por um questionário estruturado aplicado, foi possível a construção das percepções que serão aqui apresentadas.

\section{O MUSEU DE GEOCIÊNCIAS: UM MUSEU UNIVERSITÁRIO}

A Universidade Federal do Pará foi criada em 02 de julho de 1957 através do decreto no 3.191 assinado pelo então Presidente vigente, Juscelino Kubitscheck. Conta com 12 campi localizados em diferentes municípios do estado do Pará, estando em $15^{\circ}$ posição no ranking das maiores instituiçõos de ensino do país em número de matrículas. Consagra-se como a maior universidade da região Norte, sendo referência nacional e internacional em ensino, pesquisa e extensão, com mais de 60 cursos (UFPA, 2019).

Em sua grandeza, a UFPA conta com museus universitários espalhados pelo campus de Belém e dentre eles está o MUGEO. Inicialmente constituído por uma pequena coleção de minerais no ano de 1973, teve sua inauguração em 1984 em comemoração aos 20 anos do curso de Geologia da UFPA.

O museu de geociências foi fundado em 1984, foi uma ideia do professor Marcondes Lima da Costa, ele ainda é professor daqui [da UFPA] e ele é o curador do museu. Ele é o fundador e atualmente é o curador. (...) Me parece que já existia uma pequena coleção aqui (...) do Instituto de Geociências (...) mas não era tão organizada (SANTOS, 2019, informação oral).

É relevante ressaltar que o MUGEO não se preocupa apenas em a relação à UFPA, mas também com a visibilidade deste fora dos muros da universidade. Assim, o MUGEO está cadastrado no Instituto Brasileiro de Museus (IBRAM) e envia-se anualmente o relatório a esta instituição. Ademais, em uma recente pesquisa sobre os museus universitários, elaborada pelo Museu de Astronomia e Ciências Afins (MAST) que por sua vez está vinculado ao Ministério da Ciência, Tecnologia, Inovações e Comunicações, o MUGEO aparece com importante museu 
junto com outros da UFPA2 ${ }^{2}$.

O seu acervo é subdividido em duas partes: a 'Coleção Wards' e o 'Acervo geral' totalizando mais de 2.450 amostras que incluem minerais, rochas, gemas, biojóias, fósseis, dentre outras. O foco do museu está na Região Amazônica, no entanto há amostras significativas de outras partes do país e do mundo "que são catalogadas, apoiadas com fotos digitalizadas, nome, fórmula química, procedência, ocorrência geológica, doador e data da doação". (COSTA e SANTOS, 2016, p. 3).

Dentre as amostras que compõem o museu a sua maioria foi adquirida por doações feitas por professores, alunos, ex-alunos e pesquisadores do Instituto de Geociências da UFPA, ou seja, grande parte é fruto de coletas de campo de pesquisas. No entanto, alguns visitantes sentem-se à vontade para realizar doações de amostras, que, quando pertinentes à estrutura do museu, são absorvidas. Cada amostra é devidamente registrada em fichas físicas com o nome do doador, contexto geológico e observações. Segundo entrevista com o técnico do museu, as fichas permanecem arquivadas e ainda não passaram pelo processo de digitalização. Há o registro de todas as amostras, desde a primeira até a mais recente. A catalogação é feita por ordem de chegada das amostras e em média o museu recebe em torno de dez amostras por ano, não realizando de forma alguma o descarte.

A apresentação do acervo é feita por expositivo fixo, entretanto, algumas amostras ficam impossibilitadas de ser expostas devido à falta de espaço. Ademais, o mobiliário frágil de madeira já em estado de deterioração devido ao tempo, não suporta as dimensões de algumas amostras. No entanto, isso não impede que este rico acervo seja utilizado para difusão dos testemunhos da humanidade como intuito de contribuir para a educação. Esta ação, que está prevista nas diretrizes para os museus pelo ICOM, é objetivo principal do MUGEO.

O MUGEO tem como objetivo principal promover as visitas orientadas a alunos do ensino fundamental, médio e superior. Essas visitas têm como finalidade aguçar, despertar, motivar e incentivar os estudantes à pesquisa e ao interesse pela ciência da terra, bem como difundir a profissão de geólogo (COSTA e SANTOS, 2016, p. 3).

\footnotetext{
${ }^{2} \mathrm{Na}$ pesquisa "Patrimônio Cultural de Ciência e Tecnologia e Museus Universitários: pesquisa, análise e caracterização de relações estratégicas" do MAST, o MUGEO é citado juntamente com outros museus da UFPA, a saber. O Museu da Universidade Federal do Pará (MUFPA), o Museu de Anatomia da UFPA e o Museu Interativo da Física. No entanto no projeto de extensão "Museus e Acervos na Universidade Federal do Pará: construindo uma musealização em rede" e na pesquisa "Museus Universitários: uma percepção dos museus do campus Belém da UFPA", ambas desenvolvidas na UFPA, identificouse outros dois museus: Museu de Zoologia e o Centro de Memória da Amazônia, que apesar de não trazer o termo 'museu', apresenta em parte de sua organização características de museu.
} 
A divulgação também é feita de forma virtual por meio de um site ${ }^{3}$ vinculado ao Grupo de Mineralogia e Geoquímica Aplicada $(\mathrm{GMGA})^{4}$. Atrelado ao site é possível ter acesso ao Boletim do Museu de Geociências da Amazônia (BOMGEAM), que consiste em uma revista quadrimestral onde são tratados os assuntos relacionados à mineralogia, petrologia e geociências.

Para além da questão de divulgação, o museu também é um local que apoia o desenvolvimento de pesquisas, outro ponto fundamental para a constituição de um museu, principalmente no âmbito dos museus universitários (JULIÃO, 2015). Tradicionalmente temos a constituição dos museus universitários através das diversas coleções em posses das universidades, sendo elas de acesso público ou restritos a determinados departamentos, que no caso do GEOMU. Apenas as amostras que estão sendo estudadas ficam momentaneamente no interior do laboratório. Assim, percebe-se que os museus universitários colaboram para a difusão do conhecimento, estudo e produção científica acerca de suas coleções.

O museu universitário pode ser um aparelho à serviço da divulgação científica, então, outros valores devem a ele ser relacionados. Como tema recorrente, também se diz sobre a sua função educacional, não lhe sendo peculiar, já é pertinente a todo o museu. Sob o assunto, considerase as capacidades do museu universitário para educar o visitante e promover a produção do conhecimento. $\mathrm{Na}$ atualidade, além do guardar e ensinar, atribui-se outra função aos museus universitários, a de inovar (MICHELON, 2014, p. 166).

A questão da inovação dos museus é um ponto que pode vincular com a ciência, pois esta propicia tradicionalmente se relaciona com inovação. Assim sendo, observa-se a relação do GEOMU não só com as características de um museu universitário como também com a tipologia do museu de ciência e da técnica.

\section{A TIPOLOGIA DE MUSEUS DE CIÊNCIAS E DA TÉCNICA E O MUGEO}

A história dos museus de ciência e da técnica está relacionada com a criação dos museus modernos. Com a popularização dos gabinetes de curiosidade do século XIX na Europa, tem-se a posturas como a de Elias Ashmole, que doou toda a sua coleção à Universidade de Oxford, dando surgimento ao Ashmolean Museum, o primeiro museu público.

\footnotetext{
${ }^{3}$ http://gmga.com.br/\#museu

4 O GMGA é um grupo de estudos comandado pelo Prof. Dr. Marcondes Lima da Costa, onde há a junção de vários pesquisadores provenientes de diferentes instituições da Amazônia e pesquisadores do exterior. Estes estão envolvidos em técnicas de mineralogia e geoquímicas, que se aplicam aos distúrbios e recursos naturais e industriais que se encontram nesta região ou originam-se da mesma.

Complexitas - Rev. Fil. Tem., Belém, v. 4, n. 1, p. 57-65, jan./jun. 2019 - ISSN: 2525-4154
} 
Em 1759, houve a abertura de outro museu com esta configuração, o British Museum. Este se deu a partir da doação da coleção de Sir Hans Sloane, que era o médico da corte e naturalista (ALMEIDA, 2002). A partir deste período, outros nobres permitiram o acesso de forma limitada as suas coleções, ocasionando na formação de uma série de instituições museais. $\mathrm{Na}$ esteira deste boom de formação de museus, está o avanço da ciência como mote principal do século XIX.

Os museus de ciência e da técnica desenvolveram-se como instituições voltadas ao trabalho de investigação científica e preocupadas com o domínio histórico do desenvolvimento científico e tecnológico, além de representarem toda uma perspectiva de um anunciado progresso, fruto de cooperação entre ciência, técnica e indústria. As possibilidades de implicações da ciência e da tecnologia na esfera social marcam de maneira indelével o território das práticas museológicas científicas desde a primeira metade do século $\mathrm{XX}$, provocando uma proliferação de museus de ciências em diversas partes do mundo ocidental. (SOUZA, 2009, p. 157 e 158).

A partir da segunda metade do século $\mathrm{XX}$, os museus de ciência se configuram através de exposições em sua maioria interativas para a demonstração do avanço da ciência. Assim, há a preservação da memória cientifica bem como a ampliação dos espaços de educação.

Consideramos os museus de ciências espaços educacionais. Neles, as experiências vivenciadas se projetam para além do deleite e da diversão. Programas e projetos educativos são gerados, com base em modelos sociais e culturais. Seleções de parte da cultura produzida são realizadas com o intuito de torna-la acessível ao visitante (MARANDINO, 2005, p.165).

Nesta realidade que nitidamente se coloca o MUGEO, além de ser um local de pesquisa e guarda do acervo universitário, ele apresenta um significativo trabalho educativo, pois parte do acervo que está fora da composição da exposição é utilizado para fins didáticos em sala de aula. No entanto, a maioria das amostras está disponível para a visitação. Com o funcionamento de segunda à sexta-feira das $08: 00 \mathrm{~h}$ às $12: 00 \mathrm{~h}$ e das 14:00h ás 17:00h, as visitações são expressivas. Estas são feitas por meio de agendamentos prévios para que haja a preparação do conteúdo adequado para o grupo ${ }^{5}$. Há um técnico em mineração responsável por recepcionar e fazer as visitas guiadas e este conta como o auxílio dos bolsistas do Grupo PET-Geologia da

\footnotetext{
${ }^{5} \mathrm{O}$ Museu recebe diversos perfis de visitantes, dentre grupos de estudantes de escolas à grupos de universitários de diversas instituições públicas e privadas, da região metropolitana de Belém e outros municípios.
} 
UFPA. Para quem realiza sua visita de forma individual não é necessário o auxílio de guia, o que torna a visita mais livre para o eventual visitante. Além disso, é possível ver parte do acervo em eventos internos da UFPA.

Às vezes quando tem evento da Geociências aqui no Benedito Nunes ${ }^{6}$ eles pedem amostras para decoração, aí a gente leva um pedestal com as amostras, uma plaquinha. Já teve feiras, feiras do vestibular. Já teve também uma feira da Geociências que eles montaram um estande lá perto da reitoria e a gente levou (SANTOS, 2019, informação oral).

Dentre as possibilidades de apresentar o acervo fora dos muros da UFPA, destaca-se as atividades vinculadas à 'Semana Nacional de Museus', que ocorre no mês de maio em comemoração ao dia Internacional de Museus, 18 de maio. Em Belém, usualmente o MUGEO realiza sua exposição na Praça Batista Campos, localizada na região central da cidade, a fim de levar para a sociedade o conhecimento de suas amostras e realização de demonstrações de seus minerais.

Ano passado foi a Feira PanAmazônica do livro que aí o estande da UFPA, da gráfica da UFPA solicitou, aí nos levamos e ano retrasado teve lá na Estação das Docas ${ }^{7}$ a Feira de Ciência e Tecnologia que foi organizada pelo governo do Estado (SANTOS, 2019, informação oral).

Apesar da grande importância para o universo dos museus de ciência e técnica e dos museus universitários na Amazônia, o MUGEO apresenta algumas dificuldades. O mobiliário é o mesmo desde sua inauguração, mantendo layout da exposição o mesmo desde seu primórdio.

Eventualmente, quando há a quebra de um vidro ou algo similar, os responsáveis pelo museu utilizam de recursos financeiros pessoais para repor mobiliário defeituoso. A questão do espaço é outro problema enfrentado. Como o museu compartilha salas com outros setores do Instituto de Geociências, a sua expansão é inviável, por isso há uma solicitação por parte dos responsáveis para que o MUGEO para que o mesmo ocupe um novo prédio que venha a abarcar todas as suas necessidades e permitir a criação de exposições mais atraentes e estimulantes. Por não ter verba própria há problemas em realização de serviços básicos como a limpeza e conservação especializada de museus. Neste ponto vê-se a necessidade profissionais da museologia a fim de melhor realizar os serviços de conservação, documentação, dentre outras

\footnotetext{
${ }^{6}$ Benedito Nunes é o espaço de eventos localizado dentro da UFPA.

${ }^{7}$ A Estação das Docas foi inaugurada em 2000 como um complexo turístico e cultural da cidade de Belém. Anteriormente o espaço pertencia ao porto de Belém.
} 
práticas museológicas, auxiliando assim na melhoria do MUGEO no que tange as questões museológicas.

\section{CONSIDERAÇÕES FINAIS}

Este trabalho realizou uma síntese sobre o museu de Geociências da UFPA, de modo descritivo, passamos por sua gênese seguindo até a atualidade, ressaltando seu modus operandi e suas problemáticas. Além disso, destacou-se a sua importância para a divulgação das geociências e a mineralogia, compartilhando com a sua sociedade os frutos de pesquisas valiosas no âmbito nacional e internacional. O MUGEO se configura como uma instituição museal de suma importância para a região Amazônica. Mesmo com os problemas enfrentados devido à falta de verbas e a presença de profissionais da museologia, o museu cumpre o seu papel como museu de ciências e da técnica e como museu universitário.

\section{REFERÊNCIAS BIBLIOGRÁFICAS}

ALMEIDA, A. University museums audiences. Revista do Museu de Arqueologia e Etnologia, (12), 205217, 2002. Disponível em http://www.periodicos.usp.br/revmae/ article/view/109446 Acesso dia 07 de novembro de 2019.

COSTA, Marcondes. Museu de Geociências da Amazônia Uma Proposta do Grupo de Mineralogia e Geoquímica Aplicada do Instituto de Geociências da UFPA. Belém: Universidade Federal do Pará, 2013. Disponível em http://gmga.com.br/museu-degeociencias-da-amazonia/ Acesso dia 07 de novembro de 2019.

COSTA, Marcondes; SANTOS, Pabllo. Relatório de atividades do Museu de Geociências. Belém: Universidade Federal do Pará, 2016. Disponível em: http://www.ig.ufpa.br/uploads/museu/ 07-RELATORIO-DE-ATIVIDADESDO-MUGEO-ANO-2016-v2.pdf Acesso dia 07 de novembro de 2019. ICOM - Internation Council of Museums Museus Disponível em:
Complexitas - Rev. Fil. Tem., Belém, v. 4, n. 1 , p. 57-65, jan.jun. 2019 - ISSN: 2525-4154 http://www.icom.org.br/ Acesso dia 07 de novembro de 2019.

JULIÃO, Letíca Museus e coleções universitárias In.: NASCIMENTO, Adalson; MORENO, Andrea (Orgs). Universidade, memória e patrimônio. Belo Horizonte: Mazza Edições, 2015. MARANDINO, M. Museus de Ciências como Espaços de Educação In: Museus: dos Gabinetes de Curiosidades à Museologia Moderna. Belo Horizonte: Argumentum, 2005. Disponível em: https://edisciplinas.usp.br/pluginfile.p $\mathrm{hp} / 844082 / \mathrm{mod}$ resource/content/2/M ARANDINO_Museus_de_Ci\%C3\%A Ancias_como_espa\%C3\%A7os_de_e duca\%C3\%A7\%C3\%A30.pdf Acesso dia 07 de novembro de 2019.

MICHELON, Francisca Ferreira Museus Universitários: uma política para estes lugares de conhecimento Expressa Extensão. Pelotas, v.19, n.2, p. 165-168, 2014. Disponível em: https://pdfs.semanticscholar.org/adf1/ 518cd78a9704451677571b239dc0be0 80ef9.pdf Acesso dia 07 de novembro de 2019. 
ROSÁRIO, Cláudia O lugar mítico da memória Morpheus - Revista Eletrônica em Ciências Humanas Ano 01, número 01, 2002. Disponível em

http://www.seer.unirio.br/index.php/m orpheus/article/viewFile/4011/3579

Acesso dia 07 de novembro de 2019.

SANTOS, Pabllo. O Museu de Geociências. Belém: Universidade Federal do Pará - entrevista concedida em junho de 2019.

SOUZA, Daniel Museus de ciências, divulgação cientifica e informação: reflexões acerca de ideologia e memória Perspectiva em Ciência da Informação v.14, $\mathrm{n}^{\circ} 10$, p. 155-168 mai/ago, 2009. Disponível em http://www.scielo.br/pdf/pci/v14n2/v1 4n2a11.pdf Acesso dia 07 de novembro de 2019.

UFPA - Universidade Federal do Pará Histórico e estrutura Disponível em: https://portal.ufpa.br/index.php/univer sidade Acesso dia 07 de novembro de 2019.

GOMES, D. S., LOTT, W. P. O Museu de Geociências da UFPA. Complexitas - Rev. Fil. Tem. Belém, v. 4, n. 1, p. 57-65, jan./jun. 2019. Disponível em: http://www.periodicos.ufpa.br/index.php/complexitas/article/view/7785>. Acesso em: 30 de janeiro de 2020. 